\title{
The Impact of the Bologna Process \\ on the Governance of Higher \\ Education Systems in Eastern \\ Partnership Countries
}

\author{
Nicolae Toderas and Ana-Maria Stăvaru
}

\section{Introduction}

This chapter addresses the change of higher education (HE) in the Eastern Partnership $(\mathrm{EaP})$ countries from the perspective of policy coordination at central level. In this context, governance is analysed through the relationship of central government authorities with Higher Education Institutions (HEIs) and the motivating factors for adherence to Bologna Process (BP) and participation in the European Higher Education Area (EHEA). The main sources of documentation used for elaborating this chapter are research results of the authors from the last few years, especially for the case of the Republic of Moldova. These sources have been complemented by analyses and reports elaborated by European institutions and international organizations (the European Commission, the Council of Europe, the World Bank) and by official reports regarding the implementation of BP in EaP countries.

According to art. 6 of the Treaty on the Functioning of the European Union, cooperation in the field of HE belongs to the complementary competencies of the EU, which consist in actions to support, coordinate or supplement the actions of the Member States. The EU's power of change in the field of HE is a "soft power" (Polglase 2013) through which Member States cooperate in order to reach common objectives rather than reach decisions that are then implemented top-down. In spite of this limiting formal framework, over the last three decades, the EU's influence in the field of HE has constantly increased (Vögtle 2014; Sin et al. 2016) causing

N. Toderas $(\square) \cdot$ A.-M. Stăvaru

National University of Political Studies and Public Administration,

Bucharest, Romania

e-mail: nicolae.toderas@snspa.ro

A.-M. Stăvaru

e-mail: anamaria.stavaru@snspa.ro

(C) The Author(s) 2018

A. Curaj et al. (eds.), European Higher Education Area: The Impact of Past and Future Policies, https://doi.org/10.1007/978-3-319-77407-7_42 
important changes for universities, states and regions in Europe. EHEA was created in 2010 through convergence measures such as the coordination of policy actions or intensifying the exchange of experience and mutual learning. EHEA had a direct contribution to the functioning of the internal market, as well as to the intensifying of political and economic trade-relations with third countries. Cooperation in the field of HE, through BP or other instruments, is the catalyst for intensifying other policies for intergovernmental cooperation (Martens and Wolf 2009) and for changing internal policies in fields connected to HE, ranging from policies specific to economic development and market opportunities to policies related to public administration capacities. Since the second half of the 2000's, the EU's Action Plans with some countries from the Eastern neighbourhood (such as the Republic of Moldova, Ukraine, Georgia and Armenia) have made reference to cooperation and harmonisation of higher education systems (HES) in line with EU approaches and the BP principles. Both directions of actions have gradually led to the effective accession to the $\mathrm{BP}$ of the EaP countries. In order to gain access to the multiple opportunities and financial resources provided by the EU through its policies and financial instruments, EaP countries were interested in implementing reforms derived from the conditionalities established in the Action Plans. Accession to BP has been an important conditionality related to people-to-people contacts objective. Thus, the sooner the EaP countries implemented the reforms, the sooner they had access to the financial resources and technical assistance promised by the EU. In order to continue the actions for deepening intergovernmental cooperation within EHEA, the EU's Association Agreements with third countries from the EaP include objectives for strengthening the governance regime for HES, including quality assurance systems which had been institutionalized up until the moment the Association Agreements were signed.

Although the enlargement of EHEA towards the East in 2005 (Armenia, Azerbaijan, Georgia Moldova and Ukraine) and 2015 (Belarus) has brought on a revitalisation of the $\mathrm{BP}$, the dynamic of institutionalizing the new governance arrangements of the HES in EaP countries has not been researched in detail (Dobbins and Khachatryan 2015). Our research shows that in comparison to the previous decade, in the last few years many more articles, studies and policy analyses have been published regarding the dynamic of change in HES governance from EaP countries. Still, many aspects have yet to be discussed and analysed. Consequently, the enlargement of EHEA towards the East offers fertile ground for deepening the analysis regarding the ways and means of institutional change of HES in the context of processes of regional convergence, internationalisation and globalisation.

The enlargement of the BP towards countries in Eastern Europe has generated and supported a series of structural changes in the governance of their HES. Through its nature, the BP is a hybrid mechanism for policy coordination. Within the EU, it has the character of voluntary intergovernmental cooperation between Member States, putting the EU single market into practice. On the other hand, outside the EU, it has the same character of voluntary intergovernmental 
cooperation but is also accompanied by instruments for stimulation provided by the $\mathrm{EU}$ (such as access to the former TACIS or Tempus programs, or presently Erasmus +, Horizon 2020 or ENI), gaining an important capacity for supporting and guiding structural changes in certain third countries beyond the area of HE. In the case of $\mathrm{EaP}$ countries, the $\mathrm{BP}$ is a mechanism which has a convergence-promoting force (Dobbins and Khachatryan 2015). EaP countries are harmonizing their internal HE policies with approaches from countries in Western Europe in order to maximise the benefits offered by EHEA. As a result, some of them are a good example regarding the application of this convergence-promoting force, although the changes which have been made do not offer the guarantee of irreversibility. Through the convergence-promoting force (Dobbins and Khachatryan 2015), EHEA has conditioned and facilitated a process of transnational policy diffusion of market-oriented HE governance approaches and instruments from Western and Central Europe to Eastern Europe (Dobbins and Knill 2009; Dobbins 2011; Kozma et al. 2014; Vögtle 2014; Sin et al. 2016). The enlargement towards East has also generated multiple cooperation priorities for EHEA. Such is, for example, the way in which assistance is offered for institutionalising quality assurance systems so that they can become convergent with those in Western and Central Europe and be mutually recognised.

\section{The Context of Cooperation}

Being designed as a platform for multilateral cooperation between the EU and the six countries in the Eastern neighbourhood of the EU (Armenia, Azerbaijan, Belarus, Georgia, Moldova and Ukraine), the EaP is meant to diminish the barriers generated by the enlargement of the EU and the deepening of European integration. Thus, in order to avoid the isolation of the region, in 2009, the EU launched another approach for intergovernmental cooperation based on differentiation principle (Korosteleva 2017) and, from 2015, also on inclusivity principle (Sakwa 2017). The main idea was that, apart from the new areas of cooperation which would be initiated within this platform, there is a need to relaunch support for domains in which some type of cooperation already exists. Up to that moment, five of the six countries in the region had become part of the BP and were participating in the construction of EHEA. Initially, in the 2009-2013 period, the areas of cooperation in the HE field were vaguely defined, being based rather on the stipulations of action plans between the EU and partners in the region. These were not concerned with clear obligations regarding the application of BP provisions in consonance with the objectives of EHEA (Luchinskaya and Ovchynnikova 2011; Vögtle 2014; Kutsyuruba and Kovalchuk 2015) and did not lead to irreversible and sustainable changes in the governance of HES in the sense of a greater orientation towards the market and society. 
Due to the very few and inconclusive results regarding the evolution of $\mathrm{EaP}$ countries within the BP and implicitly EHEA, it was decided to redefine priorities, with a clearer specification of the objectives which needed to be reached by 2020 . Thus, for the 2014-2020 financial period of the EU, within the objective people-topeople contacts a reinforced focus on the implementation of the Bologna reforms was proposed.

We must underline that gradually, through the EaP, the EU has instituted the approach of a partnership relationship of normative pressure. This is based not only on conditionalities but also on incentives such as the participation in EU Programs, direct allocations for empowering civil society and technical assistance (including through twinning or permanent counselling from high-level experts) in priority domains. Through the EaP, the EU used a merit-based approach, expanding the application of the "more for more" principle which is "based on the premise that the more governments undertake relevant reforms, the more they will be rewarded and supported by the EU" (Schumacher and Bouris 2011). On the one hand, this principle proves to be an adequate means for encouraging processes of change which have been initiated in the field of HE. On the other hand, however, especially in situations in which reforms are stagnating, it has proved to be a demotivating factor for the actors involved in the institutionalization of the regime of market-oriented governance of HES.

The concomitant joining of the EaP countries to the $\mathrm{BP}$ has a great advantage for comparing the group dynamics. The delay is explained by the fact that in 1997, due to their participation in the Commonwealth of Independent States, there was a desire to create a common space of HE in this region (Gille-Belova 2015). The Russian Federation offered to former Soviet states a model of governance based on an approach which was different from the tendencies that were visible in Central Europe at that time-involving the market and different non-governmental actors, institutional autonomy etc. (Tomusk 2000). The late accession of the EaP countries to BP was influenced by their tendency to follow Russia's choices regarding external policy. In the second part of the last decade, the initiative of creating a common space of HE was forgotten, being later on abandoned completely by Georgia, Ukraine and the Republic of Moldova.

\section{Three Distinct Patterns of Change of Governance Arrangements}

The enlargement towards the East of the BP has brought a series of challenges to the entire process. The main challenge was that most of these countries were based on arrangements of state-control governance of HES (Dobbins 2011; Dobbins and Khachatryan 2015) due to the lack of mechanisms for public responsibility. Thus, up until effectively becoming part of the BP, their HES had the following characteristics: 
- they developed and expanded mainly in the Soviet period, without having a tradition regarding institutional autonomy and academic freedom;

- the governance arrangements were specific to the state-control paradigm of management;

- they were powerfully controlled by the government, through the shared coordination of several line ministries - the HEIs benefited from a variable institutional autonomy depending on their type and regime;

- regulation was done based on arbitrary decisions which were not founded on evidence and were non-deliberative-for example, the distribution of resources or accepting the expansion and diversification of the services offered by certain HEIs;

- the creation of parallel sets of informal arrangements had the role of eluding current regulations regarding the monitoring of quality assurance, the financing of HEIs, the creation of public or private HEIs etc., which generated an uncontrolled expansion.

Although they are not explicitly formulated in such a manner, the objectives of the BP and those of EHEA were meant to lead to the modification of the governance arrangements of HES in the sense of bringing them closer to the market and to society (Dobbins et al. 2011). Consequently, in systems in which these arrangements are defining by default and have been incorporated for hundreds and tens of years in the regulating and normative institutional frameworks, the modifications brought on by the principles of the BP and the values of EHEA cannot be ample or sudden (Dobbins 2011), but rather gradual (Vögtle 2014). On the other hand, in HES in which the institutional and normative frameworks have a state-control origin, the changes will be ample, revolutionary, thus representing a rupture from the previous arrangements. The changes can take place either suddenly, as in the case of the Baltic countries, or incrementally, as in the case of the EaP countries, although even in their case there are peaks in revolutionizing their governance systems. On the other hand, the BP and EHEA do not aspire to create a pan-European system for the governance of HES based on a top-down imposed unitary model. The essence of cooperation consists in the institutionalization of a coherent framework of coexistence of the different regimes of HES governance.

In order to compare the dynamics of the processes of consolidating the governance of HES from EaP and to determine the degree of irreversibility of the reforms which have been implemented, there is a need to clarify the factors which have motivated countries to become part of the BP and their later contribution to the creation and development of EHEA. By their aspirations of European integration, the six EaP countries can be divided into three categories. The first category is represented by countries which manifest their interest of joining the EU in the near or medium-term future (Ukraine, the Republic of Moldova and Georgia). For them, becoming part of the BP and actively participating in EHEA represents a window of opportunity for deepening both HE policies as well as adjacent domains, such as research, development, innovation. Their motivating factors were initially found in the political desire of becoming closer to the EU. In addition, for Georgia, it was 
obvious that there was a desire to dismantle the institutional arrangements inherited from the Soviet period (Glonti and Chitashvili, 2007; Dobbins and Khachatryan 2015; Jibladze 2017). In the case of Ukraine and the Republic of Moldova, such arguments were not so consistent as to motivate stakeholders to generate pressures on governmental institutions in order to establish new paradigms for managing the system. The success in transposing BP principles at the internal level represented a first piece of evidence, both for external actors as well as for the electorate, that the respective countries were capable of accelerating institutional and normative convergence and deepening these types of processes in other domains such as the liberalization of internal markets, the strengthening of institutions and democratic values etc.

Beginning from the accession to the BP and up until now, an incremental style of dismantling the old state-control arrangements of governance and replacing them with others such as state, socio or market governance predominated. The exception is represented by Georgia where, in certain stages of structural reforms of the state, several shock reforms were made for strengthening the institutional autonomy of actors within the HES (Dobbins and Khachatryan 2015), by introducing arrangements of collegial-university nature, some inspired from the USA. On the other hand, in the case of the Republic of Moldova, it took almost a decade to institutionalise a new regime of governance for HES and four attempts to adopt a comprehensive legislative framework (Toderaș and Stăvaru 2014). Each legislative project included variations from state-oriented to market-oriented HE governance regime. Although the new legislative provisions have entered into force, the system does not yet function according to the routines specific to the market-oriented governance, since the old routines based on informal policy-making arrangements still predominate.

The planned reforms proposed to institute ample changes in the governance of the systems. The amplitude of the changes was however diminished by delays in the elaboration and adoption of new education laws and, during the legislative deliberations, many of the arrangements which were going to be institutionalised were restrained (for example the modification of mechanisms for financing universities). What is more, the institutionalisation of the new arrangements was applied in a top-down manner, without offering the opportunity of adaptation (Kovtun and Stick 2009; Shaw et al. 2013, Toderaș and Stăvaru 2014). In spite of this, in the case of this group of countries, we also need to take into account the temporary variation of the impact of changes.

In a similar manner to the case of HES in Central and Eastern Europe (CEE), in this category of countries from the EaP there was a gradual transition from elitist, profoundly bureaucratic, politicized systems that were based on state-control arrangements towards systems which were much more open, collegial, and less politicized (Dobbins and Kwiek 2017; Tofan et al. 2017). There is still a need to measure and analyse the impact and effects of the institutionalisation of governance arrangements oriented towards the market and society both in a manner of policy-making, as well as research regarding institutional changes. 
The second category is represented by countries that wish to intensify their commercial relations and political dialogue with the EU, and thus diversify and maximize the advantages and facilities offered by the EU's internal market. On the other hand, they have not manifested their intention to become part of the EU and undergo corresponding structural and systemic reforms. Countries in this category are Armenia and Azerbaijan. For them, the motivating factors for becoming part of the BP were oriented towards diversifying their opportunities and facilities in education and research. In the case of Armenia, another motivating factor was also the fact that proximity to the EU was declared a key direction for the country's foreign policy, and higher education was considered as a proxy for this political objective (Matei et al. 2013). Consequently, reforms in the governance of HES were oriented more towards aspects such as increasing the quality of HE, developing qualifications systems and intensifying different types of mobility. To this end, the external assistance offered by the EU and other international donors was maximised. For example, the quality assurance system from Armenia was developed with the financial support of the World Bank (Dobbins and Khachatryan 2015; Terzian 2016), quickly becoming a model of best practice for states in the regionin spite of the fact that this system operates under the paradigm of controlling HEIs.

From the analysis of reports elaborated by different international organizations (Council of Europe, World Bank, European Commission) we can notice that for the most part, the HES in these two countries has remained excessively regulated and controlled, powerfully centralized and dependent on political decisions. Even though since becoming part of the BP important actions have been undertaken for institutionalising some market-oriented governance arrangements, the changes which have been registered are marginal and have yet to reach the desired effect.

Even though the changes are incremental, participating in EHEA contributes to the multiplication and deepening of the processes of transferring practices and approaches from HES governance regimes from other BP members. The literature findings about these two countries nuance the fact that in general, the impact of becoming part of the $\mathrm{BP}$ was a positive one.

The third category is represented by Belarus, which became part of the BP in 2015, after being denied in 2012 (Gille-Belova 2015; Dakowska 2017). Belarus is the first country for which ex-post conditionalities were imposed in order to become a member of EHEA, which refer to the implementation of the fundamental values of EHEA, being presently under a careful process of monitoring by the BFUG (Yahorau and Antashkevich 2017). Over time, Belarus developed a relatively distant attitude towards the EU, although it benefited from certain facilities of the internal market. What is more, the attitude towards the BP varied in the first part of the 2000's from an openness towards cooperation towards a political reticence regarding the membership in the 2005-2009 period and back again to a relative openness in the last few years.

The reason for joining EHEA was a political one, in the sense of diminishing political tensions with certain Western European countries and with the EU. In spite of this, the accession to EHEA was based on a limited implementation of BP provisions. For the governmental authorities, the main fear regarding the full 
application of BP provisions referred to the fact that the state would lose control over the HES (Gille-Belova 2015) and consequently, the power of the political regime would erode in time. The incentives granted by the EU through different programs proved to be inefficient, in a similar manner to the sanction measures applied by the EU to this country (Boss and Korosteleva-Polglase 2009). The main cause for the failure was precisely the enunciation by the promoters of the process of the argument regarding the spill-over effects of BP over other domains.

Reforms in the field of HE in Belarus have especially targeted the attraction of foreign students and capitalizing on research results (Polglase 2013; Gille-Belova 2015). Few actions were initiated for changing the governance system, most of which were concerned with marginal aspects in order to mime the institutionalisation of market-oriented arrangements. In reality, the governance regime has remained state-oriented, with authoritarian accents. Thus, it has not drifted far from the Soviet model of management (Gille-Belova 2014). Consequently, in comparison with the other countries in the region, the pre and post accession to EHEA changes were not ample. Taking into account the current state of affairs, the accession to EHEA has had a positive impact on the HE domestic policy. In the case of Belarus, there is still a dilemma regarding how the EHEA actors should be positioned, complementary to the conditionalities imposed prior to accession, in order to institutionalise irreversible arrangements of HES governance.

By synthesizing the three patterns, we can draw the following conclusions:

- The political motivation for becoming a BP member and for participating in the development of EHEA - with the exception of Belarus, consisted in becoming closer to the EU and maximising the benefits offered within the framework of cooperation. In the case of Georgia, even from the beginning of the preparations for accession, there was a predominant motivation of rupturing from the Soviet past and from the influence of the Russian Federation. In the case of Armenia, joining BP was an instrument to support the process of creating a new national identity (Matei et al. 2013);

- Presently, we can notice the predominance of forms of governance in which old arrangements are overlapped with new ones which are much closer to the market and society, but the state continues to play a major role. There is still confusion in the region regarding the object and functions of the new arrangements;

- The means of implementing change-non-linear and anachronic forms of implementing reforms have predominated;

- The type of change - a predominance of incremental changes, except certain contexts of abrupt change in the case of Georgia or non-change in the case of Belarus during the 2005-2011 period;

- The amplitude of change-limited harmonization based on the conditionalities of incentives that were offered.

Looking back, we can notice that important changes have taken place, such as increasing the flexibility of systems and coming closer to market-oriented governance models. In some respects, the changes are radical, of rupture from the old 
Soviet governance arrangements. The intensity of the changes varies from one political context to another. It is still questionable how fast these changes should take place and if accelerating them can guarantee the irreversibility and sustainability of the processes.

\section{Analysis of the Determining Factors Which Have Supported the Latent Institutionalisation of the New Governance Arrangements of HES}

As shown above, changes are latent but a series of spill-over effects still take place (institutional autonomy, financial diversification, quality assurance, mobility of students and teachers, lifelong learning programs etc.), which support the forces for deepening reforms by departing from authoritarian approaches and excessive control of the state. While preparing the accession to the BP the aim was to apply with priority the actions regarding the implementation of the ECTS system, switching to the three-cycle system and institutionalising new mechanisms for quality assurance. Switching to the three-cycle system was initially applied incompletely - on two cycles, bachelor and masters. The third cycle was made compatible relatively late and in the case of Belarus and Armenia, it is still not harmonized with BP provisions, presently being, among other aspects, in the stage of legislative deliberations for modifying the education law. In the case of almost all the EaP countries which became BP members, the doctoral studies cycle is still organised based on Soviet principles (Kovács 2014) although the regulations formally transposed the BP principles. The focus on the harmonization of the study cycles offered the guarantee of maximising the advantages of BP and EHEA (mobilities, recognition of qualifications and periods of study etc.). The delays are also characteristic to the objective regarding the creation and development of national frameworks of qualifications, as well as to the institutionalisation of new mechanisms for quality assurance. In September 2017, from this region, only one agency for quality assurance, the one in Armenia, was registered in EQAR. The rest of the agencies from EaP countries, except Belarus, were only affiliated, and the ministries of education had the statute of governmental member. This highlights the inefficiency of reforms which were implemented in this direction.

By retrospectively analysing the evolutions, we can notice that the BP has represented an opportunity for an ideological battle between maintaining the old arrangements for system governance and changing them in the sense of becoming close to the models from Western Europe. In all six EaP countries, the governmental authorities have used discursive rhetoric in order to sustain momentary political objectives. The rhetoric content was and is dependent on the type of relationship the respective countries have with the EU, on the one hand, and with the Russian Federation, on the other hand. The political discourse is nuanced by the ideologies promoted by the governing parties as well as by the general societal 
axiology. For example, initially in the case of Georgia and later Ukraine, the powerful rejection of the Russian Federation leads to the predominance of pro-BP arguments for intensifying cooperation within EHEA. Furthermore, the discursive use of BP in internal political battles was done out of phase under the form of contagion from one country to another. For example, at the beginning of the 2000's, the experience of the Russian Federation regarding preparations for BP accession initially represented, for national decision makers and pressure groups which supported accession to the BP of EaP countries, an obvious source of enlightenment, inspiring arguments in favour of intensifying cooperation in the field of $\mathrm{HE}$ (Tomusk 2008). The diminishing of diplomatic and economic relations of the Russian Federation with countries in Western Europe offered to pressure groups from EaP countries, which advocated for the preservation of old Soviet arrangements and against the application of BP principles, arguments for diminishing cooperation within the BP (Luchinskaya and Ovchynnikova 2011). This aspect highlights the dependency on the former decision-making centre, even though in the case of the Russian Federation the application of BP principles was much slower in comparison to the other countries in the region which became BP members in 2005.

On occasions, the influence of the Russian Federation was counteracted through the contribution of groups of experts from CEE. For example, expert groups from Romania had an important influence in configuring the new arrangements for the governance of HES in the Republic of Moldova (Toderaş 2012), as well as those from Poland in the case of Ukraine (Dakowska 2017) and Georgia. Moreover, many critical points of view came from the Central and Western Europe regarding the low performance of EaP countries in terms of achieving the objectives of BP and attaining stability and coherence of their HES.

In comparison to the anti-BP discourse from the Russian Federation, Central and Western Europe offered alternatives for action which were compatible with the Western-European models of systemic governance of HEIs. Processes of modernization and decoupling from the Soviet past were encouraged, subject to the fact that the effects of EHEA on the internal stability of HE will be mainly negative (brain-drain, lack of coherence in professional training, the expansion of foreign universities etc.). Whether they were positive or negative, the ideological influences regarding the $\mathrm{BP}$ and EHEA proved to be useful mechanisms for contagion in cascade within EaP countries, thus strengthening deliberation and public reflection regarding the adoption of their own styles for HES governance.

Apart from the financial incentives granted by the EU through the Tempus and TACIS programs, the activity of pro-PB pressure groups was supported through top-down mechanisms. For example, an important role was played by UNESCO-CEPES (Conley Burrows 2017; Dakowska 2017), Council of Europe, as well as Open Society Foundations (Matei et al. 2013; Toderaș and Stăvaru 2014; Terzian 2016; Dakowska 2017). Still, because their actions were sporadic, they did not manage to support, at least at the rhetorical level, actions for reforming HES governance. 
In the entire region, we can notice the persistence of a non-deliberative framework of policy-making which leads to the imitation of reform processes (Yahorau and Antashkevich 2017). The actions were mainly voluntary, without having mechanisms for direct pressure, targeting relatively small circles of civil servants with no direct access to political decision-making. Thus, the bottom-up mechanisms which were created proved to be relatively fragile and did not last for long after the grants were depleted. This is why the region is characterised by a limited capacity for reflection and internal deliberation regarding the opportunity and way of changing the relationship between the state and HE institutions, in order to ensure institutional and policy convergence with western HE models. Furthermore, BP promoters were not so active as to be able to explain at the external level the nature of internal changes and, respectively, at the internal level, the nature and types of arrangements for system governance, as well as of the tendencies for changing them. For example, Matei et al. (2013) underline that there are no academic or other forums in Armenia to discuss the state of affairs and perspectives of higher education.

In a similar manner to countries from CEE, in this region, the institutionalisation of the new governance arrangements depends on political conjectures, as well as on the ideology of governing parties. For example, in the case of the Republic of Moldova, the process of creating a national agency for quality assurance lasted several years due to uncertainties and political blockages, in spite of the fact that the organizational and procedural design of the agency and of the quality assurance process existed since 2008 (Bischof 2016). In all the countries in the region, due to the lack of a participative policy-making system, the decisions of institutions which participate directly or indirectly in the governance of HES are implemented in a top-down manner, thus eliminating certain categories of stakeholders from the deliberative process, such as students or employers.

\section{Efficiency and Sustainability of the Processes of Change Dilemma}

From the multiple monitoring reports and analyses of the current state of affairs, we notice that in the case of EaP countries there is a persistent lack of trust with regard to continuing the reforms and the irreversibility of changes in the absence of pressures, conditionalities or complementary external incentives. The entire region still remains dependent on external financial assistance, expertise and logistics. Consequently, there is still a dilemma about how can EaP countries be empowered from the perspective of the normative power of EHEA in order to make the processes of consolidating the governance of HES irreversible.

In spite of the fact that in this area the BP was interpreted since the early 2000's as a component of the EU's external policy, the process of becoming members of the BP and the presence in EHEA are of intergovernmental nature. In this regard, 
the Action Plans and Association Agreements are vaguely formulated. Consequently, in order to ensure that the reforms which are implemented are sustainable and irreversible, there is a need to use the normative-power approach of the EU in the manner of a convergence-promoting force by ensuring more openness, the intensification of mobility (similar to CEEPUS) and of mutual learning. Clearer monitoring mechanisms are necessary, as in the case of reforms regarding the economic liberalization or those in the field of justice. In the context of current discussion regarding the results of EaP from 2020, there is a need to place more accent in the following period on monitoring and qualitative evaluation of the processes of changing the governance regimes of HES in this area based on a set of common results indicators, as well as a set of customized indicators for each country in the region. Measures of support have to be differentiated, customised according to the specificities and adequate to the needs and capacities of each country. Within the BFUG, a special working/advisory group can be created for monitoring the achievement of indicators and for offering methodological support and expertise. In order to increase the level of knowledge regarding the reforms which have been implemented and the implications of actively participating in EHEA, the results of monitoring and evaluations need to be communicated in a language accessible to different types of audiences.

Incentives such as "more for more" or "less for less" sometimes prove to be ineffective due to the fact that they are oriented towards the quantitative-mimetic implementation of reforms, without generating comprehensive processes of reflection and deliberation. Of course, a good implementation of reforms requires time and complementary resources. Being conducted within EHEA and under the auspice of ENI, reforms can contribute to strengthening trust and diminishing the amplitude of the rhetoric against reforms and the intensification of cooperation within EHEA.

\section{Conclusions}

The chapter offers an overall view of the tendencies of change in $\mathrm{HE}$ in EaP countries in connection with the BP. The main conclusion that can be drawn is that there is no single pattern of change. After over 12 years of membership in BP of the majority of countries in the region, they still need to be analysed case by case. The general impact of enlarging the BP towards the East is a positive one, however, and the governance of national HE systems has changed significantly in comparison to the period before accession. The amplitude of the changes largely depended on the political context of each EaP country and the incentives offered by the EU or international donors.

In the EaP area, the motivation for joining $\mathrm{BP}$ was used either to accelerate European integration or for the benefit from the advantages of intergovernmental cooperation in the field of HE (maximising opportunities for mobility, participating 
in EU initiatives etc.) without attempting to join the EU. After the EaP countries became part of the BP, there was no direct and explicit pressure from the EU regarding reforms implementation. In consequence, there was no approach based on global progress indicators but only on interventions financed through EU funds. Thus, the institutionalization of new governance arrangements was made based on intermittent processes.

The approach gradually changes, and BFUG, in its capacity of executive structure supporting the BP, already has a series of leverages through which it can contribute to making the changes more dynamic, as well as ensuring the efficiency and sustainability of the processes of change. Considering the current priorities of the ENP are better formulated and even oriented towards stimulating reforms in HE, this presents an opportunity for EU Member States to actively become involved through bi- or multilateral cooperation in supporting EaP countries to overcome the major discrepancies between the East and the West.

\section{References}

Bischof, L. (2016). The QUAEM project in the context of the development of quality assurance in the Republic of Moldova. In M. Middell, V. Reinhardt, \& L. Bischof (Eds.), From quality assurance to strategy development in the Moldovan higher education: Stakeholder perspective (pp. 113-123). Leipziger Universitätsverlag.

Boss, G., \& Korosteleva-Polglase, E. (2009). Changing Belarus? The limits of in Eastern Europe. Conflict and Cooperation, 44(2), 143-165.

Conley Burrows, L. (2017). The European Centre for higher education: A UNESCO effort to reduce cold war tensions and to promote co-operation in higher education in Europe. Comparative Civilizations Review, 76(11), 70-90. Retrieved from http://scholarsarchive.byu. edu/ccr/vol76/iss76/10.

Dakowska, D. (2017). Competitive universities? The impact of international and European trends on academic institutions in the 'New Europe'. European Educational Research Journal, 16(5), 588-604.

Dobbins, M. (2011). Higher education policies in Central and Eastern Europe: Convergence towards a common model? Palgrave Macmillan.

Dobbins, M., \& Khachatryan, S. (2015). Europeanization in the "Wild East"? Analyzing higher education governance reform in Georgia and Armenia. Higher Education, 69(2), 189-207.

Dobbins, M., \& Knill, C. (2009). Higher education policies in Central and Eastern Europe: Convergence towards a common model. Governance, 22(3), 397-430.

Dobbins, M., \& Kwiek, M. (2017). Europeanisation and globalisation in higher education in Central and Eastern Europe: 25 years of changes revisited (1990-2015). European Educational Research Journal, 16(5), 519-528.

Dobbins, M., Knill, C., \& Vögtle, E. M. (2011). An analytical framework for the cross-country comparison of higher education governance. Higher Education, 62(5), 665-683. https://doi. org/10.1007/s10734-011-9412-4.

Gille-Belova, O. (2014). Les réformes de l'enseignement supérieur en Biélorussie: Entre poids de l'héritage soviétique et influence internationale diffuse. Revue d?études comparatives Est-Ouest, 45(1), 55-90.

Gille-Belova, O. (2015). Beyond the limits of the European higher education area: The case of Belarus. European Journal of Higher Education, 5(1), 83-95. 
Glonti, L., \& Chitashvili, M. (2007). The challenge of Bologna: The nuts and bolts of higher education reform in Georgia. In V. Tomusk (Ed.), Creating the European area of higher education: Voices from the periphery (pp. 209-226). Springer.

Jibladze, E. (2017). Reforms for the external legitimacy in the post Rose Revolution Georgia: Case of university autonomy. Hungarian Educational Research Journal, 7(1), 7-27.

Korosteleva, E. A. (2017). Eastern partnership and the Eurasian Union: bringing "the political" back in the eastern region. East European Politics, 33(3), 321-337.

Kovács, K. (2014). The Bologna process in the Ukraine. In T. Kozma, M. Rébay, A. Óhidy, \& É. Szolár (Eds.), The Bologna process in Central and Eastern Europe (pp. 321-353). Springer.

Kovtun, O., \& Stick, S. (2009). Ukraine and the Bologna process: A case study of the impact of the Bologna process on Ukrainian State Institutions. Higher Education in Europe, 34(1), 91-103.

Kozma, T., Rébay, M., Óhidy, A., \& Szolár, É. (2014). The Bologna process in Central and Eastern Europe (pp. 13-32).

Kutsyuruba, B., \& Kovalchuk, S. (2015). Stated or actual change in policy terrain? Review of the literature on the bologna process implementation within the context of teacher education in Ukraine. Journal of Ukrainian Politics and Society, 1(1 SRC-BaiduScholar), 33-57.

Luchinskaya, D., \& Ovchynnikova, O. (2011). The Bologna process policy implementation in Russia and Ukraine: Similarities and differences. European Educational Research Journal, 10 (1), 21-33.

Martens, K., \& Wolf, K. D. (2009). Boomerangs and Trojan horses: The Unintended consequences of internationalising education policy through the EU and the OECD. Springer, Netherlands, 26, 81-107.

Matei, L., Iwinska, J., \& Geven, K. (2013). Higher education in Armenia today: A focused review. Report for the Open Society Foundation Armenia. Budapest: CEU Higher Education Observatory.

Polglase, G. (2013). Higher education as soft power in the Eastern Partnership: The case of Belarus. Eastern Journal of European Studies, 4(2), 111-121.

Sakwa, R. (2017). Europe and the political: From axiological monism to pluralistic dialogism. East European Politics, 33(3), 406-425.

Schumacher, T., \& Bouris, D. (2011). The revised European neighbourhood policy: Continuity and change in policy. In D. Bouris \& S. T. (Eds.), The revised European neighbourhood policy: Continuity and change in EU foreign policy (pp. 1-33).

Shaw, M. A., Chapman, D. W., \& Rumyantseva, N. L. (2013). Organizational culture in the adoption of the Bologna process: A study of academic staff at a Ukrainian university. Studies in Higher Education, 38(7 SRC-BaiduScholar), 989-1003.

Sin, C., Veiga, A., \& Amaral, A. (2016). European policy implementation and higher education: Analysing the Bologna process. Palgrave Macmillan.

Terzian, S. (2016). International influences on Post-Soviet Armenian education. European Journal of Education, 51(2), 281-294.

Toderaş, N. (2012). Opening the European higher education borders: Case study on the policy transfer from Romania to the Republic of Moldova. Eurolimes, 14, 145-158.

Toderaș, N., \& Stăvaru, A. M. (2014). The use of impact evaluation and evidences at the internal level the higher education reform in the Republic of Moldova. Annals of the University of Oradea International Relations and European Studies (RISE), 4, 125-138.

Tofan, A., Bischof, L., Huisman, J., Smolentseva, A., Froumin, I., \& Palgrave, C. (2017). Higher education system dynamics and institutional diversity in Post-Soviet countries: The case of Moldova. In J. Huisman, A. Smolentseva, \& I. Froumin (Eds.), 25 Years of transformations of higher education systems in Post-Soviet Countries. Reform and Continuity: Palgrave Macmillan.

Tomusk, V. (2000). When East meets West: Decontextualizing the quality of East European higher education. Quality in Higher Education, 6(3), 175-185. 
Tomusk, V. (2008). The Bologna process and the enlightenment project: A bird's eye view from the bottom of the slope. European Education, 40(2), 9-28.

Vögtle, E. M. (2014). Higher education policy convergence and the Bologna process.

Yahorau, A., \& Antashkevich, S. (2017). Higher education reform in light of Bologna process: Opportunities, obstacles, context. In Recommendations for Eastern Partnership countries, Eastern Partnership Civil Society Forum. Retrieved from https://eap-csf.eu/index.php//01/31/ higher-education-reform-in-light-of-bologna-process-opportunities-obstacles-context.

Open Access This chapter is licensed under the terms of the Creative Commons Attribution 4.0 International License (http://creativecommons.org/licenses/by/4.0/), which permits use, sharing, adaptation, distribution and reproduction in any medium or format, as long as you give appropriate credit to the original author(s) and the source, provide a link to the Creative Commons license and indicate if changes were made.

The images or other third party material in this chapter are included in the chapter's Creative Commons license, unless indicated otherwise in a credit line to the material. If material is not included in the chapter's Creative Commons license and your intended use is not permitted by statutory regulation or exceeds the permitted use, you will need to obtain permission directly from the copyright holder.

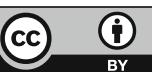

